\title{
Can the Other be Heard? Response to Commentaries on 'Omphile and his Soccer Ball'
}

\author{
By Finex Ndhlovu \\ University of New England, Australia
}

Email: fndhlovu@une.edu.au

\section{Introduction}

I welcome the invitation to a right of reply that Multilingual Margins journal has extended to me; and I thank all nine discussants for sharing their thoughts on my paper 'Omphile and his soccer ball: Colonialism, methodology, translanguaging research'. Eight of the nine discussants (Kathleen Heugh, Alan Carneiro, Manuel Guissemo, Kanavillil Rajagopalan, Zannie Bock, Lynn Mario T. Mendezes de Sousa, Nana Aba Appiah Amfo, and Torun Reite) provided what I consider to be balanced critiques that highlight both the strengths and weaknesses of the paper. One reader, Don Kulick, did not find anything positive about the paper. Instead, he raised numerable objections that are pitched in a somewhat confrontational tone that is radically at odds with the views proffered by all other discussants. For this reason, I decided to organise my response into three short sections. The first is a rejoinder that builds on and engages those critical points raised by the eight discussants who are overall in concert with each other. In the second section I provide a rebuttal of Don Kulick's review, which I find to be largely dismissive and bereft of any semblance of collegial engagement with the arguments advanced in the paper. I then close with a short paragraph that reiterates my original invitation to engage in dialectical conversations about how best to carry out social science research projects in ways that are consistent with the quite contemporary anti-colonial, anti-foundational and transformative agenda being pushed by decolonial and other like-minded scholars.

\section{Rejoinder - response to eight discussants}

In addition to affirming the motivations and lines of argument I advance, nearly all eight reviewers noted some limitations - of one form or another - which is to be expected. Most of the points raised are comments that further clarify some of my propositions that had not been fully explicated; for which I am grateful. In my reply, I, therefore, focus on four crucial points that feature 
prominently in the reviews. The first one is about the idea that there is 'translanguaging theory'. This concern was raised by Kathleen Heugh and also picked up by two or three other readers - though expressed differently. Heugh says "I am not convinced that many scholars agree that there is, or should be, a definitive or stable pedagogy or theory of translanguage. So, it worries me that Ndhlovu indicates that there is a "translanguaging theory" (Heugh, this issue). I take Heugh's point and agree with her reservations. The impression that there is a uniform body of thought that constitutes a 'translanguaging theory' is clearly a consequence of slippages on my part. Looking at the paper again in the light of this comment, I can now see the dangers of assuming that a translanguaging theory does exist. As Heugh (this issue) cautions, the idea of a translanguaging theory "would take us back to assumptions of the universality of knowledge and reason ... re-scripting neo-colonial habitus and hegemonic supremacy of colonial thinking". This is precisely what my paper sought to question. When I was on a fellowship at the Graduate Center, City University of New York Graduate in the fall of 2017, I had numerous conversations with Ofelia García about the pitfalls of reinforcing the very same Euro-modernist hegemonic thinking that we are seeking to avoid. Though she is one of the key proponents of translanguaging, Ofelia García consistently admitted that the challenge we face is how to chart new alternative paths using a language that allows us to de-link from the colonial matrices of power that are firmly ensconced in the body-politic of the academy. It is here that Heugh's clever notion of 'trickster habitus' comes in handy. A careful rethink of the terminology we use to characterise translanguaging and other allied approaches is required as a way to avoid obscuring debates.
The second point is about what Kanavillil Rajagopalan perceives as lack of "any proof of a direct link between colonialism and the phenomenon of translanguaging" (Rajagopalan, this issue). I would like to clarify that I do not believe that there is a direct link between translanguaging and colonialism. It seems Rajagopalan may have misunderstood what I meant in my discussion of translanguaging in relation to colonialism. The point I was trying to put across is this: though proponents of translanguaging are driven by the anti-colonial agenda, the empirical data that supports their theoretical suppositions seems to continue being generated through the conventional scientific method, which is a legacy of colonial modernity. I, however, do agree that this particular aspect of the discussion could have been expressed much better in order to avoid giving an impression of causal link between translanguaging and colonialism. I would like to thank Rajagopalan for bringing greater clarity into the discussion. In particular, he raises a significant point in saying "It may well be the case that translanguaging is what there was at the very beginning. Somewhere along the line distinct languages were formed in tandem with the rise of nation-states and all" (Rajagopalan, this issue). Often, when sociolinguists talk about the co-construction of languages and nation-states they trace the argument to Benedict Anderson's (1991) Imagined Communities. But I think Rajagopalan's review is pushing the debate further, towards a bold, combative and more productive direction inviting us to probe the geo- and body-politics of knowledge that is hidden beneath the self-serving interests of Western epistemology (Mignolo, 2009: 4).

The third and most significant line of enquiry that I had completely overlooked in the paper is the question of research 
ethics and informed consent. Three commentators - Zannie Bock, Nana Aba Appiah Amfo and Torun Reite - weighed into this glaring omission in the paper. As a member of the Human Research Ethics Committee of my university, I should have had this aspect of research at the forefront of my thinking while writing the paper and I thank all three readers for drawing my attention to it. As Amfo (this issue) rightly points out in relation to the autoethnographic methodology that I advance in the paper, "the glaring challenges of this approach, particularly those bothering on ethics have to be confronted and addressed rather than muted". Reite draws our attention to the problem of "unintentionally continuing to colonize (or at least abuse) the people that we as researchers encounter". These are, indeed, very real unintended consequences of relying on autoethnographic methodology, which require our serious consideration. For this reason, I wish to extend an open invitation to the scholarly community involved in this type of work, for robust ongoing conversations on how best to go about with decolonial research in a manner that puts ethics and informed consent at the centre. I think there are at least two crucial questions that we need to exercise our minds on: How are matters of research ethics consideration to be framed and articulated in decolonial projects? And how do current institutional and national policies on research ethics impinge on the discourse and praxis of decolonial epistemological research? I believe addressing these questions is germane because current understandings of research ethics (at institutional, national or international levels) are indexically linked to the apparatus of colonial normative scientific methods that we are seeking to unsettle. In some of my previous projects, particularly with indigenous, migrant and refugee communities, I have had prospective research participants decline an invitation to participate as soon as I tell them there is a consent form to be signed. But this is part of the national guidelines and local institutional requirements on conducting research with humans in an ethically acceptable way. Instuitional Human Research Ethics Committees would insist on evidence of informed consent, often in the form of a signed consent form. How do we reconcile this? Is there a possibility for decolonising research ethics such that it also incorporates indigenous participants' understandings of 'informed consent'? Or, alternatively: Is a decolonial epistemology of research ethics possible, and what might it look like?

The fourth and final point I would like to address in this section is about gender discourse and positionality of the researcher, which appears in Torun Reite's review. Though it had not crossed my mind at the time of writing the paper, I think Reite is correct in saying the encounter with Omphile and the interaction that followed would have played out differently if the researcher was white, female and possibly not a speaker of the linguistic codes that feature in the story. This is a fair and welcome intervention that, in my view, has potential to inform the ways we deploy autoethnography. As Reite argues it is important to reflect the positionalities of gender, race/ethnicity, language abilities and context. I doing so, we can open a window for entering into "further deliberations on the biographies and also the geographies of the researcher and their relation to the biographies and geographies of those they encounter" (Reite, this issue).

In closing this section, I wish to reiterate that the goal of my paper was to invite scholars working in this area of research to join the conversation I initiated around the troubling question 
on the reification of conventional Euromodernist epistemologies that continue to be treated as if they were of a natural kind; the only valid and legitimate ways of reading and interpreting the world. The eight commentators provided several other useful insights that I would have wanted to build on and extend further but time and space do not permit. I now turn to my reply to Don Kulick's review.

\section{Rebuttal - Reply to Don Kulick}

I would like to open this section by taking the reader back to the motivations of my paper. I wrote the paper as an invitation to the social-scientific community to take stock of and reflect on the common sense assumptions of conventional scientific methods that guide the way we do research. For this reason, I was not seeking consensus; neither did I expect all readers to be sympathetic to my line of argument. I would have been surprised if this were to be the case because I did not intend to be doctrinaire in my propositions - though I am delighted that eight out of the nine commentators concurred with the overall thrust of my thesis. The point of greater significance here is that this paper speaks from a very specific locus of enunciation; that of decolonial epistemology. The argument I advance joins the long list of pioneering international social science theorists from the Global South who argue in support of the promises that an ecologies of knowledge paradigm holds for articulating the possibilities of epistemological pluralism (de Sousa Santos, 2007; Mignolo, 2002; Kovach, 2009; Bagele, 2012 and Smith, 2009). This is against the backdrop of the dominance of Euro-modernist epistemologies that make general claims to universal relevance while turning a blind eye to the fact they are only a part of a diverse global system of knowledges. This ideological habit that universalises dominant epistemologies overlooks two important points: that throughout the world there are very diverse forms of knowledge; and that there are many and very diverse concepts of what counts as valid and legitimate knowledge (de Sousa Santos, 2007).

From the onset, I made it clear that:

The style of presentation I use departs slightly from conventional academic narrative techniques in that it does not have the usual elements of a research essay such as research methods and procedures, research design, sampling techniques, and so on. This is because the article is a reflective piece that reports on a random unplanned observation of naturally-occurring communicative practices (Ndhlovu, this issue, page $3)$.

Therefore, evaluating the paper through the lens of Euro-modernist epistemology (as Don Kulick has done) misses the whole point of the argument advanced. To the extent that there was anything to learn from Kulick's review, it was all obscured by the acerbic tone of his report, which is quite unfortunate. Kulick opens his review with a tirade and follows through with series of negative hyperbolical expressions about the paper and myself. I am not going to dignify these with a response except to make the following four points. First, seeking to ridicule and diminish the ontological density of scholars whose views we have misread, at worst - or we disagree with, at best - is a futile exercise that does not help advance the science. Kulick's review betrays an angry man who has been personally offended by a paper that not only challenges but also refuses to toe the line of Euro-modernist value judgements about what constitutes valid 
and legitimate forms of research. As a senior professor, I suppose Kulick knows, as well as most of us do, that the contest of ideas has always been and still remains the hallmark that defines the academic enterprise - and that disagreement has to be done in a manner that recognises the fact that there are multiple ways of reading and interpreting the world. For this reason, I believe Kulick could have done well to defend the legacy of Euro-modernist epistemologies without necessarily sounding angry and personally offended by the position I advance in the paper.

Second, Kulick introduces his commentary by characterising the tone of my paper as "combative". I agree; though I contest the claim that his response is couched in an equally combative tone (he sounds like an angry and offended man - I explain this under point number four below). Decolonial theorists like myself accept the "combative" label as a badge of honour because we are deliberately and necessarily engaged in 'epistemic disobedience' (Mignolo, 2009) - that counterhegemonic struggle which calls for epistemological pluralism. Part of our task is to engage with the historical debates surrounding the colonial origins of mainstream scientific methods in the context of the Global South. In a 2017 article aptly titled 'Decolonising Research Methodology Must Include Undoing its Dirty History', Sabelo Ndlovu-Gatsheni provides a lucid account of the history of conventional Euro-modernist methodologies; how they emerged as handmaiden of colonialism and imperialism; as well as how, in the end 'research' became a critical part of the imperial colonial project. Ndlovu-Gatsheni (2017: 3) goes further and argues:

Our present crisis is thatwe continued to use re-search methods that are not fundamentally different from before. The critique of methodology is interpreted as being anti-research itself ... Consequently, methodology has become straightjacket that every researcher has to wear if they are to discover knowledge. This blocks all attempts to know differently. It has become a disciplinary tool that makes it difficult for new knowledge to be discovered and generated.

Scholars who try to exercise epistemic disobedience (like I did in my paper) are disciplined into an existing methodology, thus draining them of their profundity. There is no better way to describe the intentions of Kulick's review than what Ndlovu-Gatsheni says in the above quotation. But it is about time defenders of Euro-modernist epistemological hegemony got used to the fact that it is no longer business as usual. They better get used to not only listening to themselves and start listening to other voices, especially those articulating opposing and 'unfamiliar' views from the Global South. Decolonial and Southern theorists are seized with the task of unmasking the role and purpose of research; they are shifting the phenomenology of research in order to "re-position those who have been objects of research into questioners, critics, theorists, knowers, and communicators" (Ndlovu-Gatsheni, 2017: 4). Scholars of Southern and Decolonial persuasions have voices too and will not allow their voices to be silenced any longer - all for challenging Euro-modernist epistemologies and their misdirected claims to universal relevance. At the heart of it all is the fact that forms of knowledge that are produced following only one tradition of knowing are partial, biased and, to a large degree, incomplete. This is because no single type of knowledge - on its own - can account for all possible interventions in the world (de Sousa Santos, 2007). Dani Wadada Nabudere (2011: 1) could not have put 
it any better when he said mainstream Euro-American scientific knowledge and theorisation alone is unable to explain everything about the world because there is "great deal of uncertainty in the way we understand the world, as well as in the way human beings understand each other in different environments and cultural contexts". Writing nearly one and half decades ago, Immanuel Wallerstein reminded us that:

$[W]$ e live in a very exciting era in the world of knowledge, precisely because we are living in a systemic crisis that is forcing us to reopen the basic epistemological questions and look to structural reorganizations of the world of knowledge. It is uncertain whether we shall rise adequately to the intellectual challenge, but it is there for us to address (Wallerstein, 2004: 38).

The conventional scientific tradition that Kulick seeks to defend is not immune from the changing dynamic in the global knowledge economy. In this vein, I wish to reiterate the cross-cutting argument of my paper. My goal is to invite the progressive scholarly community to engage in conversations that probe the universalisation of Western thought that imposes normative criteria and standards for evidence, validity, coherence and intelligibility in knowledge production and dissemination (Buendia, 2003; de Sousa Santos, 2002).

Third, in his dismissal of the story that motivated me to write the paper and the prognosis I proffer for methodological innovations, Kulick says (i) that the seven-line recollection of my interaction with Omphile is way too small and insignificant for us to read anything meaningful out of it; and (ii) "Why should we trust that the author's memory of this unexpected interaction was not only accurate, but exact? (Kulick, this issue; emphasis in the original).
Both points may hold sway, but only to a limited extent because all personal stories rely on memory and recollection. So, this is not something unique to the story that undergirds my paper. Kulick then uses this as an opportunity to dismiss the way I deploy the insights of autoethnography. He argues that a better way to illustrate the potential benefits of autoethnography would have been for me to examine "memoirs that foreground, precisely, speakers' reflections on their life in language: Eva Hoffman's Lost in Translation, Alice Kaplan's French Lessons, and Vladmir Nobokov's Speak, Memory..." (Kulick, this issue). There is no doubt that these memoirs are valuable resources. But the authors of these memoirs also relied on their memories and recollections just like I did in telling the story of my encounter with Omphile - unless of course Kulick wants us to believe that these people had pre-recorded their entire life stories, with prior knowledge that such information would come handy someday when they write their memoirs. I, therefore, have great reservations with what I see as Kulick's privileging of the written word (so-called literacy) over orality as an authentic and reliable source of information. This is consistent with Euro-modernist habits and practices that I critique in the paper. The point I am arguing here did not escape the attention of Nana Aba Appiah Amfo who had this to say:

Autoethnography which allows an engagement of the readers in a personal narrative from the author is in sync with oral narrative traditions of many African cultures. Oral story-telling traditions have for generations been an authentic avenue to pass knowledge down across generations. The narrative power and feature of autoethnography is reminiscent of the time-tested method through which members of many African 
communities make sense of their world, share knowledge and teach important aspects of their cultures" (Amfo, this issue).

Memory and recollection are the centre-piece of story-telling; and admittedly, orality does have its own limitations, but so does the written word, which is open to author subjectivity and bias. Both are not infallible and should not be immune from criticism. So, in my view, both oral and written stories (regardless of how long or short they are) should be evaluated on their own merits by taking into account issues such as cultural context and purpose of story-telling.

As I have already indicated above, another aspect of Kulick's dismissal of the story of my interaction with Omphile is that the data is too small, which implies he is in favour of big data. I do not have any major qualms about this except to say that though big data is useful for some ends, it does not help us answer all questions in every context, particularly questions that relate to issues occurring at the micro-social levels of society. Small datasets such as the story I narrate in the paper encourage us to be specifically attentive of the small details of everyday life that may contain the potential to develop or question big theories (Strathern, 2004: xx). This is about the spheres of possibilities presented by asking big questions of small data. As Amfo (this issue) concurs, the arguments I advanced in the paper provide "an example of how small data can be useful window through which we can understand our varied worlds."

The fourth aspect of my rebuttal is this. I would suggest that there is in Kulick's response evidence of what postcolonial critics characterise as internal contradictions of colonialism or the colonial mindset (Sur, 2005; Phillip, 2004; and Radhakrishna,
2000). The typical modus operandi of colonial habits and practices is that they fundamentally proceed through affirmation and denial - in equal measure. Kulick affirms the importance of paying attention to the smallest detail, no matter how insignificant it may seem. But in the same breath, he denies the potential transformative power of such minute detail, especially in relation to theory building by Southern scholars like myself. It appears that in his defence of the conventional Euro-modernist tradition of research Kulick wants scholars from the Global South (and their communities) to be content with being suppliers of raw data (as evidenced by his lifelong anthropological work among Southern communities) and not producers of new and alternative theoretical frameworks. This is a classic contradiction of the highest order - and yet not quite surprising because it reflects the colonial habitus of which it is a part.

But scholars speaking and writing from the Global South have had enough of being told that they do not have the right to theorise and we refuse to take such condescending habits and practices lying down. After more than 500 years of Euro-North American epistemological domination, we shall not allow ourselves to continue being bullied and humiliated into silence and submission. We are determined to defend our inalienable right to epistemic freedom.

\section{Conclusion}

I conclude my reply by reminding the reader of the original inspirations of the paper, which Kathleen Heugh captures a lot better than I had probably done:

Ndhlovu's paper is an invitation. It is an invitation to engage in dialectical conversations, such as his conversation with Omphile. It is through such conversations that we may find opportunities to engage 
in critical reflexivity about our own epistemologies, systems of beliefs and ways of being, and how these influence our view of the world and how we try to disentangle webs of deceit spun by the trickster habitus of coloniality. Omphile offers us a metaphor for disentanglement (Heugh, this issue).

This call did not escape the attention of all commentators, but one.

\section{References}

Anderson, B. 1991. Imagined Communities: Reflections on the Origins and Spread of Nationalism. London \& New York: Verso.

Buendia, E. 2003. Fashioning Research Stories: The Metaphoric and Narrative Structure of Writing Research about Race. In G. Lopez \& L. Parker (Eds.), Interrogating Racism in Qualitative Research Methodology (pp. 49-69). New York: Peter Lang.

Chilisa, B.2012. Indigenous Research Methodologies. Los Angeles, London 7 New Delhi: Sage.

De Sousa Santos, B. 2002. Toward a Multicultural Conception of Human Rights. In B. Hernandez-Truyol (Ed.) Moral Imperialism: A Critical Anthology (pp. 39-60). New York: New York University Press.

De Sousa Santos, B. 2007. Beyond Abyssal thinking: From Global Lines to Ecologies of Knowledges. Revista Critica de Ciencias Sociais, 80. Retrieved from http://www. eurozine.com/articles/2007-06-29-santosen.html.
Kovach, M. 2009. Indigenous methodologies: Characteristics, Conversations, and Contexts. Toronto: University of Toronto Press

Mignolo, W.D. 2002. Geopolitics of Knowledge and the Colonial Difference. South Atlantic Quarterly 103(1): 57-96.

Mignolo, W.D. 2009. Epistemic Disobedience, Independent Thought and De-colonial Freedom. Theory, Culture E Society 26(7-8): 1-23.

Nabudere, D. W. 2011. Afrikology, Philosophy and Wholeness: An Epistemology. Pretoria: Africa Institute of South Africa.

Ndlovu-Gatsheni, S. 2017. Decolonising Research Methodology Must Include Undoing Its Dirty History. The Conversation, 27 September 2017. https:// theconversation.com/decolonisingresearch-methodology-must-includeundoing-its-dirty-history-83912.

Phillip, K. 2004. Civilising Natures: Race, Resources, and Modernity in Colonial South India. New Brunswick: Rutgers University Press.

Radhakrishna, M. 2000. Colonial Construction of a 'Criminal' Tribe: Yerukulas of Madras Presidency. Economic and Political Weekly 35(28-29): 2553-2563.

Smith, L. T. 2009. Decolonizing Methodologies: Research and Indigenous Peoples. London \& New York: Zed Books.

Strathern, M. 2004. Partial connections. Rowman \& Littlefield Publishers: Lanham.

Sur, A. 2005. Contradictions of Colonialism. Science as Culture 14(1): 93-96.

Wallerstein, Immanuel. 2004. Uncertainties of Knowledge. Philadelphia: Temple University Press. 